\title{
LA CORRUPCIÓN: PSICOPATOLOGÍA
}

\author{
Sinonimia: Cáncer social, gangrena moral, hedor social, "olor a pescado podrido". \\ Martín Nizama Valladolid ${ }^{(1)}$ \\ Universidad Nacional Mayor de San Marcos, Lima, Perú \\ (RECIBIDO EL 1/9/2008, ACEPTADO EL 02/12/2008)
}

\begin{abstract}
RESUMEN
Se elabora una sistematización fenomenológica de la corrupción; grave proceso mórbido espiritual, cuya génesis se remonta a los orígenes de la humanidad. Actualmente es una pandemia en la sociedad anética y deshumanizada, regida más por los antivalores. En el Perú, la corrupción no tuvo registro en la Época del Tahuantinsuyo. Esta se inició en la Época Colonial con la presencia de los conquistadores, quienes la introdujeron en la sociedad peruana; y continuó en la Época Republicana hasta la actualidad, habiéndose convertido en un grave problema de salud espiritual, con impacto devastador en todos los campos de la realidad social, hasta convertirse en un factor de desestabilización del Estado y de ingobernabilidad. Seguidamente se presenta el perfil psicosocial disfuncional del peruaño; se formula una definición de la corrupción como un grave trastorno espiritual, en el cual el individuo carece de conciencia del daño que ocasiona a sus semejantes. Se abordan sus características, etiología, fenomenología y estructura. También, se mencionan los diversos escenarios de la corrupción, sus principales manifestaciones, la institucionalidad disfuncional en sus formas aberrantes: La institucionalidad informal y la institucionalidad oculta. Luego se describe la cultura escatológica, el lenguaje de la corrupción con las expresiones más comunes del acervo popular y la imagenología de las cúpulas dirigentes. Así como el síndrome de la corruptela política, la semiología correspondiente y las secuelas de la corrupción. Finalmente, unas reflexiones sobre este trastorno y las alternativas pertinentes con el propósito de contribuir a erradicarlo del seno de la sociedad.
\end{abstract}

Palabras clave: Corrupción, psicopatía social, comportamiento anético.

\begin{abstract}
It elaborates a phenomenologic systematization of corruption; a serious spiritual morbid process, whose genesis starts since the origin of humanity. Nowadays, it`s pandemic in the anethic and dehumanized society, which is ruled by antivalues. In Peru, corruption was not registered in the Tahuantinsuyo empire. It began in the Colony when the conquerors introduced it into our society; and it has continued through the Republic period until our days. It has become a serious problem to our spiritual health, with a devastating impact in every field of our social reality, until it became a factor of destabilization of the state and ungovernability. It presents a , dysfunctional psicosocial profile of Peruvians; defines corruption as a serious

1 Docente Principal de la Facultad de Medicina de la UNMSM. E-mail:maniva@terra.com.pe
\end{abstract}


spiritual disturbance, in which the individual suffers of a lack of conscience of the damage caused to his fellowmen. The characteristics, etiology, phenomenology and structure are discussed. Also, the different stages of corruption, its main manifestations, the dysfunctional institutionality in its aberrant forms. The informal institutionality, and hidden institutionality, the eschatological culture has been described, the more common expressions of the language of corruption and the image of corrupted leaders. As well as the syndrome of corrupted politics, its semiology and its consequences. Finally, some reflections of this disturbance and the appropiate alternatives with the purpose of contributing in the eradication of this from the heart of the society.

Keywords: Corruption, social psycopathy, anethic behavior.

\section{INTRODUCCIÓN}

La corrupción es un cáncer espiritual que corroe las entrañas más profundas de la humanidad, con grave impacto en el desarrollo humaño y en desmedro del capital social en la "pequeña aldea global". Afecta de manera devastadora al Estado, las instituciones, la célula familiar y al individuo, con secuelas degradantes y disruptivas. Sus elevados índices la han convertido en uno de los más grandes problemas de la posmodernidad, si no el mayor, por el daño económico, político, ético y moral que acarrea en la población mundial y nacional.

Sus inicios se remontan a los orígenes de la humanidad. La biblia relata la felonía de Judas quien vendió a Jesús por unas cuantas monedas. Las mil y una noches, los libros de Los vedas, Los diálogos socráticos, La ilíada, La odisea, La eneida, El ingenioso caballero don Quijote de la Mancha, El criticón y La divina comedia, entre otras obras de la literatura clásica, refieren hechos de corrupción. Por ejemplo, Shakespeare, refiriéndose a la corrupción hizo decir a Hamlet: "algo se pudre en Dinamarca". También, en la concepción cristiana, de los siete pecados capitales, la soberbia, la avaricia, la lujuria, la gula y la pereza tienen relación directa con la corrupción.

En la posmodernidad está en auge la sociedad anética, en la cual imperan los antivalores: vacuidad, intereses económicos, mercado salvaje, hedonismo, odio, envidia, egolatría, insensibilidad, banalidad, violencia y corrupción. La sociedad anética es individualista, materialista y deshumanizada, adherida a la banalidad y la estulticia, en la cual tiene plena vigencia el pensamiento de Francisco de Quevedo y Villegas (1580-1645): "Poderoso caballero es don dinero". Incluso, han sido propuestos los siete pecados sociales: 1 . Riqueza sin trabajar, 2. Placer sin conciencia, 3. Conocimiento sin educación, 4. Ciencia sin humanidad, 5. Negocios sin moral, 6. Fe sin sacrificio y 7. Política sin principios. Por lo demás, es harto sabido que en el quehacer de la política cotidiana existe un axioma: Política, poder, dinero, corrupción y lujuria van siempre de la maño, de espaldas al pudor. En ella, según Macchiavello, con la argucia de la razón de Estado, el fin justifica los medios. En este contexto, cabe parafrasear a Martin Luther King: "Peor que la corrupción es el silencio de los justos". Entre nosotros, Saúl Peña, desde la perspectiva psicoanalítica apunta: "El traumatismo histórico, la cultura del crimen, la tortura y la corrupción dan lugar a una patología del lazo social. Es obligación nuestra hacer escuchar a la sociedad y a la humanidad lo que ella no está dispuesta a escuchar y no quiere creer" [6]. 
En la cultura nacional, durante el imperio del Tahuantinsuyo (S. XII-S. XVI) se creó un eficaz muro de contención anticorrupción, mediante la aplicación implacable de tres principios ético-morales: Ama sua, no robar; Ama quella, no ser perezoso y Ama llulla, no mentir. No existe registro de actos de corrupción en el incanato. En la Época Colonial (1522-1821), se inicia la corrupción cuando en la ciudad de Toledo, el 26 de julio de 1529, la Reyna Isabel (de Portugal), esposa del Rey Carlos V firmó la capitulación con Francisco Pizarro, dándole al conquistador los mismos poderes que poseía el Rey. De modo que los funcionarios que llegaron a América estuvieron investidos con el mismo poder que ostentaba el monarca. Es más, los corregidores, encomenderos y demás delegados de la corona se regían por el apotegma: Acato la ley pero no la cumplo. Así, tuvieron licencia para cometer todo tipo de tropelías, perversidades e iniquidades. Por ejemplo, el engaño de Pizarro al Inca Atahualpa, el embuste religioso del cura Valverde, la doble moral de la Iglesia Católica, las atrocidades de la Inquisición, la subasta de cargos públicos, cobros subrepticios, impuestos abusivos, la ominosa esclavitud; así como la inicua explotación del indio, el envilecimiento de la población aborigen y el genocidio de más de 12 millones de indígenas. Mientras que en la Época Republicana (1821-2008), los pensadores peruaños desnudaron la corrupción de la manera siguiente: Gonzales Prada afirmó, "En el Perú, donde se pone el dedo brota la pus" y dejó para la posteridad esta catilinaria, "Acabemos con el pacto infame de hablar a media voz". Jorge Basadre: "El Perú carece de clase dirigente; sólo tiene clase dominante"; la malversación del Tesoro Público, en "Lima fue grande y en provincias monstruosos"; y Mario Vargas Llosa, en su libro Conversación en la Catedral, a través de su personaje Zavalita se pregunta: “¿En qué momento se jodió el Perú?". Y, en la actualidad, con proverbial vergüenza, podemos sentenciar que los peruaños nadamos en la pus de la corrupción $[1,2,3,4,5,6]$. De modo que este trastorno mórbido en el Perú es un lastre de antigua data, cebada por la codicia, impudicia, impunidad, lenidad y la complicidad.

Entre tanto, el perfil psicosocial disfuncional del peruaño es como sigue: inmadurez, amnesia, huachafería, conformismo, mediocridad, desidia, impuntualidad, desorganización, improvisación, imprevisión, mesianismo, sumisión, actitud pasivo-agresiva, desconfianza, desesperanza, fatalismo, facilismo, oportunismo, arribismo, envidia, chisme, intriga, maltrato y revanchismo. Un vasto caldo de cultivo para la corrupción en una población vulnerable.

\section{Definición}

La corrupción es un grave trastorno espiritual que consiste en la corrosión ética y moral, personal, grupal y social, con la consecuente perversión del pensamiento, la conducta y la sensualidad. Su propósito es el beneficio personal y/o grupal, en desmedro del interés social. Es cebada por el egoísmo, la codicia, mezquindad, estulticia y el cinismo; sin conciencia del daño que se ocasiona al prójimo ni de las secuelas que se causan a la sociedad o a la nación. 


\section{Características}

Daño de la integridad, virtud o principios morales; inducir a lo incorrecto por métodos ilegales; utilización del poder político o de los privilegios de un cargo público para conseguir beneficios personales y hacer amoral a una persona, costumbre o tradición.

\section{Etiología}

La corrupción es un fenómeno mórbido, complejo, multicausal, entre las cuales cabe mencionar las siguientes: desamor, egolatría, vacío espiritual, avaricia, sensualidad, impunidad y lenidad, escala axiológica débil/ausente, paradigmas negativos, conflicto de intereses, permisividad, tolerancia social, silencio cómplice y búsqueda de dinero fácil y/o poder.

\section{Fenomenología}

Su esencia es la carencia o debilidad de la escala axiológica a la cual se adiciona el desamor al prójimo, la avaricia, la lujuria y la egolatría. Por este motivo, la corrupción es un proceso mórbido de índole espiritual, económica, social y cultural solapado, insondable e irreductible, por acción de quienes lo practican en forma activa o pasiva, apoyados por el silencio cómplice y por soterradas redes de clientelismo, corrosivas; circuitos o grupos de poder omnímodo, chantajista y extorsionador. Es orquestada por los hilos invisibles del arte del engaño, la manipulación, la seducción y la maquinación $[4,5,8]$.

\section{Estructura}

Este fenómeno corrosivo comprende: corrupción activa, corrupción pasiva, estrategia, logística, encubrimiento, redes de apoyo, silencio cómplice e impunidad y la cultura escatológica.

\section{Escenarios de la corrupción}

Existen diversos escenarios de corrupción:

$\begin{array}{lll}\text { Personal } & \text { Empresarial } & \text { Religiosa } \\ \text { Familiar } & \text { Comercial } & \text { Profesional } \\ \text { Social } & \text { Judicial } & \text { Mediática } \\ \text { Política } & \text { Policial } & \text { Gremial } \\ \text { Gubernamental } & \text { Castrense } & \text { Institucional } \\ \text { Burocrática } & \text { Académica } & \text { Virtual }\end{array}$




\section{Manifestaciones}

Las principales manifestaciones de la corrupción son:

Espionaje

Soborno

Extorsión

Tráfico de influencias

Lobbies

Lavado de dinero

Tráfico ilícito de drogas

Redes invisibles

Institucionalidad aberrante

Tráfico de armas

Corrupción de funcionarios
Enriquecimiento ilícito

Prevaricato

Concusión

Nepotismo

Fraude

Secretismo

Compra de puestos públicos

Impudicia

Oportunismo

Aprovechamiento

Mercado negro

\section{Institucionalidad disfuncional}

La débil institucionalidad formal o convencional tiene su contraparte aberrante:

\section{La institucionalidad informal}

Constituida por personal acostumbrado a proceder según su criterio y en función de sus intereses personales, al margen de la legalidad y de la normatividad vigente. Su poder es fuerte y suele imponerse a la institucionalidad convencional, mediante la argucia, las malas artes, la presión sostenida y la manipulación por parte de cúpulas anéticas de toda calaña.

\section{La institucionalidad oculta}

Conformada por grupos y redes solapadas de poder mafioso, cuyo propósito es apoderarse de las instituciones para depredarlas en beneficio particular, poniendo la institucionalidad al servicio de su insaciable codicia en desmedro de los intereses de la institución que representan. Son avezados en el arte de la guerra psicológica, la guerra sucia y el acogotamiento vil de autoridades. Es el hedor, el agujero negro de la institucionalidad disfuncional. Su poder es maligno.

\section{La cultura escatológica}

Se le define como la expresión de la miseria humana en sus niveles más abyectos y repulsivos, al servicio del odio, la envidia, la avaricia y la mezquindad más ruin. Se expresa mediante libelos anónimos, voladas, rumor, denigración, infamación, intriga y chisme. También se le denomina cultura cloacal, cultura de zaguán o coprocultura. 


\section{Lenguaje de la corrupción}

Las expresiones idiomáticas de mayor arraigo popular relacionadas con la corrupción son, entre otras, las siguientes:

"Ladrón de cuello y corbata"

"Borrón y cuenta nueva"

"En el Perú, la justicia se compra"

"Después te explico"

"No te preocupes, yo me encargo de todo"

"Vacas sagradas"

"Papelito manda"

"De mañas y artimañas mucho saben las alimañas"

"La manzana podrida corrompe a las demás"

"Olor a pescado podrido"

"Miente, miente que algo queda"

"Las medias verdades son peor que las mentiras"

"Con tal que me dé de comer que robe nomás"

"Repartija: "Repartirse la torta"

"Rabo de paja"

"Mamadera del Estado"

"Honorarios de éxito"

"Habrá robado pero ha hecho obra"

"El dinero que robó no era del Estado; era del narcotráfico"

"El mejor cliente es el Estado"

“QQuién no ha robado?”. "Todos roban”

“Y, cuál es la mía?”

"Soy su hermaño pero no sé nada"

"Hecha la ley, hecha la trampa"

"Para mis amigos todo y para mis enemigos la ley"

"Se levantó el Perú en ruedas"

“Romper la maño". Cutra.

"Coimisión". "Movida" 
"Usted dirá, con cuanto nos apoya"

"Planillas ocultas". "Planillas doradas"

"Es conversable"

"El honor es su divisa y el empalme su sonrisa"

"Habla, ¿cómo es? Tú dirás. Yo sólo escucho"

"Tragamonedas" (Policía corrupto)

"Hemos hecho un faenón hermaño"

"Rata, ratón o insecto"

"Aceitar". "Operar". "Bisturí".

"Cocodrilos del mismo charco"

"Ladrón de cuatro esquinas

"Ladrón de siete suelas"

"Cómo le gusta la mermelada"

\section{Imagenología de las cúpulas dirigentes}

Sin caer en abusivas generalizaciones, los "vladivideos", "vladiaudios", "petroaudios", "petromails", comunicaciones y agendas, han revelado que no pocos miembros de las cúpulas dirigentes del país: políticas, tecnocráticas, empresariales, militares y sociales, poseen comportamientos anéticos:

Doble juego Avaricia Carencia de identidad

Doble moral Indolencia Oportunismo

Doble cara Manipulación Felonía

Amoralidad Artimañas Incapacidad de sentir culpa

Sed de poder $\quad$ Malas artes

\section{Síndrome de corruptela política}

En el escenario político global, nacional y local, es común comprobar el siguiente síndrome psicopatológico:

Maquiavelismo Demolición de los valores éticos y morales

Mendacidad Sed de poder

Mecida Histrionismo patético

Mesianismo Perfidia 
Servilismo y obsecuencia

Golpismo

Gobierno de cúpula

Corrupción

Polarización política

Enquistamiento en el poder

Autocracia
Cinismo

Indolencia

Soberbia

Desinformación

Fragmentación social

Impunidad

Derrumbe moral

\section{SEMIOLOGÍA}

\section{Espionaje telefónico "Chuponeo". "Pinchar"}

Interceptación telefónica clandestina para grabar las conversaciones privadas de las personas, violando su intimidad, con propósitos perversos.

\section{Videoespionaje "Ampay". "Vladivideos".}

Grabación fílmica clandestina de la vida íntima o privada de las personas para luego exponerlas al escarnio público o chantajearlas.

\section{Limpieza de imagen "Blanqueo". "Lavar la cara"}

Maniobras y estrategias manipulatorias dirigidas a limpiar la imagen de personajes públicos caídos en descrédito. Por ejemplo: campaña mediática desplegada para presentar ante la opinión pública al dominicaño Fortunato Canaán, como un bien intencionado empresario dispuesto a invertir en el Perú en los rubros de extracción de petróleo, construcción de hospitales y cárceles, energética, etc; ocultando que lo hacía utilizando a un lobbista posicionado en las altas esferas del poder político para evadir las licitaciones y, por ende, al órgaño de control público correspondiente: Consejo Superior de Contrataciones y Adquisiciones del Estado (CONSUCODE).

\section{Soborno}

"Romper la maño". "Aceitar"

Acción de ofrecer dinero, dádivas o prebendas a alguien, para obtener de él un favor o beneficio. Pago que se hace a una autoridad para que simule desconocer la trasgresión y de este modo impedir que se aplique la Ley, logrando la impunidad.

Ejemplo: Sendos videos permitieron visualizar en la televisión el pago que efectuó el eximio corruptor Vladimiro Montesinos Torres a políticos, empresarios y directores de diarios, para comprar su conciencia política; así como a determinados medios de comunicación y ponerlos al servicio de la campaña re-reelecionista de su mentor y jefe político, Alberto Fujimori. 


\section{Tráfico de influencias}

"Vara". "Padrinazgo"

Es la utilización de un cargo público para obtener beneficios propios por sobre los intereses sociales o nacionales. V.gr. Todo un gabinete ministerial tuvo que renunciar por el escándalo mediático y social del caso "petrogate" (negociado de concesión de lotes para exploración de petróleo).

\section{Lavado de dinero}

"Blanqueo de dinero"

Legalizar el dinero mal habido mediante la utilización de organizaciones de fachada y/o utilización de testaferros. El alcalde de Pucallpa y un empresario aerocomercial fueron encarcelados acusados de lavado de activos en cantidades fabulosas.

Tráfico ilícito de drogas "Narcotráfico". "Narcococaleros". "Narcos". "Narcopaís" Negocio con drogas ilícitas a través de organizaciones mafiosas que ganan pingües cantidades de dinero sucio. Cultivo e intento de legalización de los cultivos de hoja de coca para las organizaciones mafiosas. Por ejemplo: las zonas rojas: Cusco, Huánuco, el VRAE (Valle de los ríos Apurímac y Ene). Igualmente, intensas campañas publicitarias destinadas a impulsar la legalización de la marihuana orquestadas por organizaciones camufladas y apoyadas por personalidades desinformadas.

\section{Contrabando}

Mercado negro. "Contra”

Introducción y venta clandestinas de mercaderías prohibidas o sometidas a derechos arancelarios demasiado elevados, defraudando al tesoro público.

\section{Corrupción de funcionarios "Coima". "Coimisión"}

Sobornar funcionarios públicos para interferir o manipular su conducta funcional en beneficio de ocultos intereses particulares. Caso "petrogate".

\section{Enriquecimiento ilícito}

"Peces gordos"

Acumulación de dinero mal habido con escandalosos signos exteriores de riquezas, producto de negocios turbios, operaciones económicas ilegales y aprovechamiento ventajista de las posiciones de poder.

\section{Tránsfugas}

"Vendidos". "Otorongos"

Personajes políticos que venden su conciencia política al mejor postor, traicionando a su electorado o seguidores. Por ejemplo: transfuguismo de congresistas. "Otorongo no come Otorongo". 
Planillas doradas

Mamadera". "Burocracia dorada". "Comechao"

Sueldos burocráticos exorbitantes que se asignan a sí mismos los burócratas de las cúpulas del poder mediante planillas secretas o camufladas.

\section{Lobby "Contactos". "Relaciones". "Honorarios de éxito"}

Grupo no convencional que ejerce presión sostenida sobre autoridades y funcionarios públicos, para obtener negocios ventajosos con el Estado. Actúan en base a influyentes contactos partidarios, empresariales y sociales. Por ejemplo: lobista prófugo que se entregó voluntariamente a la justicia luego de 38 días de clandestinidad, por el caso del "petrogate".

\section{Sobrevaloración y subvaluación "Cutra"}

Dolo consistente en la alteración de los precios de bienes y servicios según la conveniencia de los proveedores, en contubernio con los responsables de adquisiciones al interior de las instituciones.

\section{Malversación}

Delito que cometen las autoridades o funcionarios que sustraen o consienten que un tercero sustraiga caudales o efectos públicos que tienen a su cargo. Uso de dinero del tesoro público para fines no previstos, no presupuestados ni programados.

\section{Mecer \\ "Huevear"}

Entretener a alguien con engaños. Por ejemplo: encarcelar a los corruptos por un tiempo corto para simular justicia, luego dejarlos libres para que disfruten de lo robado por el resto de su vida.

\section{Poder mafioso}

“Capos".

Red de personajes corruptos que actúan en forma orquestada, concertada y a la sombra del poder político, administrativo o social, con la finalidad de perpetrar sus fechorías o de protegerse de la acción de la justicia en aras de la impunidad o lenidad. Recurren a la artimaña, triquiñuela, componenda, patraña, extorsión, chantaje y aniquilamiento.

\section{Operativos psicosociales "Cortina de humo". "Arte del engaño". "Cojudeo Social”}

Acciones encubiertas para demonizar o demoler a un adversario político. También alarmar, escandalizar o intimidar a la opinión pública, distrayendo su atención con impactos mediáticos de cobertura local, regional o nacional, para que se olvide del problema crítico 
de fondo. Ejemplo: La virgen que llora, el retorno de Sara Helen, presencia del curandero Texeira, histriónico operativo policial del ex presidente Fujimori simulando la captura de su siamés Montesinos.

\section{SECUELAS}

Este trastorno espiritual maligno acarrea consecuencias sociales funestas, a menudo, irreversibles. Principalmente:
Añomia
Atraso social
Pobreza y extrema pobreza
Insensibilidad
Exclusión social
Deshumanización
Rencor, resentimiento u odio
Injusticia social
Infelicidad
Canibalización
Sufrimiento
Lumpenización familiar, colectiva e institucional
Desesperanza colectiva
Delincuencia
Fatalismo
Irracionalidad social
Depresión masiva
Autodestrucción y heterodestrucción masiva
Baja autoestima
Pérdida de valores
Insatisfacción social
Cultura de la corrupción
Adicción al dinero
Debilitamiento del Estado
Fragmentación social
Mengua de la democracia
Brechas sociales abismales
Psicopatización social
Fundamentalismo
Crimen organizado
Confrontación social
Indignación social
Violencia indiscriminada
Crisis de gobernabilidad
Antros de corrupción
Depredación de la biodiversidad
Falta de oportunidades
Devastación ecológica
Estado mafioso
Contaminación ambiental
Redes de poder oculto
Recalentamiento global
Castas privilegiadas
Conflictos sociales 


\section{REFLEXIONES}

¿Existen grupos de genes de la corrupción en el genoma humaño?

En los albores del tercer milenio hemos ingresado a la era de la sociedad anética, en la cual prevalecen los antivalores?

¿Vivimos en una sociedad canibalizada donde prevalecen la ley del vale todo y la ley de la selva?

¿Hay una democracia para el primer mundo y otra muy distinta para el tercer mundo?

¿Cuál es la responsabilidad ética de los organismos internacionales como la OEA, la ONU o de las potencias mundiales como Estados Unidos, la Unión Europea o China ante los hechos de corrupción cometidos en los más altos niveles de poder del Estado?

¿Cuánta hipocresía hay en la lucha contra la corrupción de parte de los organismos anticorrupción estatales?

¿Cuál es la catadura ética y moral de cierta clase política internacional y nacional, dispuesta a sacrificar los valores democráticos a cambio de intereses encubiertos?

¿Qué paradigmas ético-morales representaron Fujimori, Montesinos y su camarilla para la juventud peruana?

Personajes con cero credibilidad, sin la confianza de la opinión pública y con una imagen deteriorada irreversiblemente, debieron seguir gobernando un país políticamente convulsionado e indignado

¿Por qué los peruaños permitieron que una red criminal y corrupta se apoderara fácilmente del país, lo depredara y devastara tan impunemente?

¿La inmadurez de la población es una de las causas principales de la corrupción en el Perú?

¿Por qué los peruaños presentan amnesia social?

¿El Perú es un país inviable? ¿Un país enfermo? ¿Ingobernable?

¿El Perú siempre será un país gangrenado por la corrupción?

¿Quo vadis Perú?

\section{ALTERNATIVAS}

Para frenar y acabar con esta gangrena social se formulan las siguientes propuestas:

Saneamiento integral de la administración de justicia.

Poner fin a la impunidad mediante una legislación que penalice la corrupción como delito de lesa humanidad.

Que las organizaciones de derechos humaños contemplen el sufrimiento del pueblo como consecuencia de la corrupción y se sumen a la instrumentalización de una legislación drástica. 
Que las organizaciones internacionales de la más alta jerarquía apoyen resueltamente a los gobiernos en su lucha contra la corrupción.

Cesar la retórica de la mera condena e implementar una política de hechos que ataque el problema desde sus raíces.

Crear un sistema anticorrupción con jueces, fiscales y policías probos; con autonomía administrativa y económica.

Vertebrar un vigoroso movimiento social anticorrupción sostenido, con apoyo político y económico en todo el país.

Valorar la reserva moral de la sociedad.

Educación humanista sustentada en valores democráticos, con paradigmas positivos.

Impulsar el desarrollo humaño sostenible

Movilización de la sociedad peruana contra la corrupción generalizada existente en el país y en pro de los valores éticos y morales

Educar a los niños desde el hogar.

\section{REFERENCIAS BIBLIOGRÁFICAS}

1. Castillo, Evaristo (2001). La conjura de los corruptos. Tomo 1. Narcotráfico. Lima: Editorial Brasa S.A.

2. Gonzales, Guillermo (editor) (2001). Los escaños de Montesinos. Testimonios de una entrega sin condiciones. Lima: impreso en Fimart S.A.C.

3. Jochamowitz, Luis (2002). Vladimiro, vida y tiempo de un corruptor. Expediente I. Lima: El Comercio Ediciones.

4. Nizama, Martín (2001). La década dantesca del Perú. Visón de un psiquiatra. Lima: Editorial Milla Batres.

5. Nizama, Martín (2008). "Psicopatía Política. Caso Fujimori". Revista de Investigación en Psicología vol. 11, N. ${ }^{\circ}$ 1. Lima: Instituto de Investigaciones Psicológicas de la Universidad Nacional Mayor de San Marcos.

6. Peña, Saúl (2003). Psicoanálisis de la corrupción. Política y ética en el Perú contemporáneo. Lima: PEISA, p. 58.

7. Ramírez, Ramón (2002). Los jueces de Montesinos. La mafia fujimontesinista en el poder judicial. Lima: Academia de Magísteres y Doctores del Perú (AMADP).

8. Rospigliosi, Fernando (2000). El arte del engaño. Las relaciones entre los militares y la prensa. Lima: Tarea Asociación Gráfica Educativa. 